University of South Florida

DIGITAL COMMONS

Digital Commons @ University of

@ UNIVERSITY OF SOUTH FLORIDA

South Florida

Internal Medicine Faculty Publications

Internal Medicine

$11-1-2012$

\title{
Transgenic Overexpression of Matrix Metalloproteinase-9 in \\ Macrophages Attenuates the Inflammatory Response and Improves Left Ventricular Function Post-Myocardial Infarction
}

\author{
Rogelio Zamilpa \\ University of Texas Health Science Center at San Antonio \\ Jessica Ibarra \\ University of Texas Health Science Center at San Antonio \\ Lisandra E. de Castro Brás \\ University of Texas Health Science Center at San Antonio \\ Trevi A. Ramirez \\ University of Texas Health Science Center at San Antonio \\ Nguyen Nguyen \\ University of Texas Health Science Center at San Antonio
}

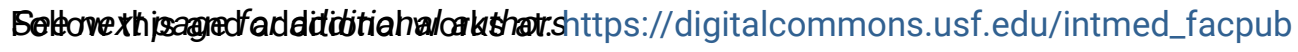

\section{Scholar Commons Citation}

Zamilpa, Rogelio; Ibarra, Jessica; de Castro Brás, Lisandra E.; Ramirez, Trevi A.; Nguyen, Nguyen; Halade, Ganesh V.; Zhang, Jianhua; Dai, Qiuxia; Dayah, Tariq; Chiao, Ying Ann; Lowell, Wesley; Ahuja, Seema S.; D'Armiento, Jeanine; Jin, Yu Fang; and Lindsey, Merry L., "Transgenic Overexpression of Matrix Metalloproteinase-9 in Macrophages Attenuates the Inflammatory Response and Improves Left Ventricular Function Post-Myocardial Infarction" (2012). Internal Medicine Faculty Publications. 63. https://digitalcommons.usf.edu/intmed_facpub/63

This Article is brought to you for free and open access by the Internal Medicine at Digital Commons @ University of South Florida. It has been accepted for inclusion in Internal Medicine Faculty Publications by an authorized administrator of Digital Commons @ University of South Florida. For more information, please contact digitalcommons@usf.edu. 


\section{Authors}

Rogelio Zamilpa, Jessica Ibarra, Lisandra E. de Castro Brás, Trevi A. Ramirez, Nguyen Nguyen, Ganesh V. Halade, Jianhua Zhang, Qiuxia Dai, Tariq Dayah, Ying Ann Chiao, Wesley Lowell, Seema S. Ahuja, Jeanine D'Armiento, Yu Fang Jin, and Merry L. Lindsey 


\title{
Transgenic Overexpression of Matrix Metalloproteinase-9 in Macrophages Attenuates the Inflammatory Response and Improves Left Ventricular Function Post-Myocardial Infarction
}

\author{
Rogelio Zamilpa, Ph.D. 1,2,3, Jessica Ibarra, Ph.D. ${ }^{4}$, Lisandra E. de Castro Brás, Ph.D. 1,2,3, \\ Trevi A. Ramirez, B.A. ${ }^{1,2,3}$, Nguyen Nguyen, M.S.E.E. ${ }^{1,5}$, Ganesh V. Halade, Ph.D. ${ }^{1,2,3}$, \\ Jianhua Zhang, M.D.,Ph.D. 1,2,3, Qiuxia Dai, M.D. ${ }^{1,2,3}$, Tariq Dayah, M.D. ${ }^{1,2,3}$, Ying Ann \\ Chiao, Ph.D. ${ }^{1,2,3}$, Wesley Lowell, B.S. ${ }^{1,2,3}$, Seema S. Ahuja, M.D. ${ }^{1,4}$, Jeanine D'Armiento, \\ M.D.,Ph.D. ${ }^{6}$, Yu-Fang Jin, Ph.D. ${ }^{1,5}$, and Merry L. Lindsey, Ph.D. ${ }^{1,2,3}$ \\ ${ }^{1}$ San Antonio Cardiovascular Proteomics Center, The University of Texas Health Science Center \\ at San Antonio \\ ${ }^{2}$ Barshop Institute of Longevity and Aging Studies, The University of Texas Health Science \\ Center at San Antonio \\ ${ }^{3}$ Division of Geriatrics, Gerontology and Palliative Medicine, The University of Texas Health \\ Science Center at San Antonio \\ ${ }^{4}$ Division of Nephrology, Department of Medicine, The University of Texas Health Science Center \\ at San Antonio \\ ${ }^{5}$ Department of Electrical and Computer Engineering, University of Texas at San Antonio \\ ${ }^{6}$ Department of Medicine, Columbia University
}

\section{Abstract}

Following myocardial infarction (MI), activated macrophages infiltrate into the necrotic myocardium as part of a robust pro-inflammatory response and secrete matrix metalloproteinase-9 (MMP-9). Macrophage activation, in turn, modulates the fibrotic response, in part by stimulating fibroblast extracellular matrix (ECM) synthesis. We hypothesized that overexpression of human MMP-9 in mouse macrophages would amplify the inflammatory and fibrotic responses to exacerbate left ventricular dysfunction. Unexpectedly, at day 5 post-MI, ejection fraction was improved in transgenic (TG) mice (25 $\pm 2 \%$ ) compared to the wild type (WT) mice $(18 \pm 2 \%$; $\mathrm{p}<0.05)$. By gene expression profiling, 23 of 84 inflammatory genes were decreased in the left ventricle infarct (LVI) region from the TG compared to WT mice (all $\mathrm{p}<0.05$ ). Concomitantly, TG macrophages isolated from the LVI, as well as TG peritoneal macrophages stimulated with LPS, showed decreased inflammatory marker expression compared to WT macrophages. In agreement with attenuated inflammation, only 7 of 84 cell adhesion and ECM genes were increased in the TG LVI compared to WT LVI, while 43 genes were decreased (all $\mathrm{p}<0.05$ ). These results reveal a

(c) 2012 Elsevier Ltd. All rights reserved.

Address for Correspondence: Merry L. Lindsey, Ph.D., Department of Medicine, Division of Geriatrics, Gerontology and Palliative Medicine, The University of Texas Health Science Center at San Antonio, 15355 Lambda Drive, MC 7755, San Antonio, TX 78245, (phone) 210-562-6051; (fax) 210-562-6110; lindseym@uthscsa.edu.

Publisher's Disclaimer: This is a PDF file of an unedited manuscript that has been accepted for publication. As a service to our customers we are providing this early version of the manuscript. The manuscript will undergo copyediting, typesetting, and review of the resulting proof before it is published in its final citable form. Please note that during the production process errors may be discovered which could affect the content, and all legal disclaimers that apply to the journal pertain.

Disclosures

None 
novel role for macrophage-derived MMP-9 in blunting the inflammatory response and limiting ECM synthesis to improve left ventricular function post-MI.

\section{Keywords}

myocardial infarction; matrix metalloproteinase-9; extracellular matrix; inflammation; cardiac remodeling; mice; macrophage

\section{Introduction}

After myocardial infarction (MI), circulating monocytes in the bloodstream infiltrate into the injured myocardium and differentiate into macrophages [1]. Macrophage infiltration into the necrotic myocardium can be detected by day 3 and peaks by day 5 post-MI [2,3]. The degree of macrophage activation plays a critical role in the cell-mediated inflammatory response that follows MI. Macrophage activation post-MI is biphasic and consists of an initial pro-inflammatory phase that overlaps with an anti-inflammatory phase [2]. Proinflammatory macrophages, also known as M1 or classically activated macrophages, have increased production of inflammatory mediators such as interleukin-1 beta (IL-1 $\beta$ ), interleukin-6 (IL-6), tumor necrosis factor alpha (TNFa), and MMP-9. Pro-inflammatory macrophages promote extracellular matrix (ECM) degradation [4]. In contrast, antiinflammatory macrophages, also referred to as M2 or alternatively activated macrophages, have increased production of anti-inflammatory mediators such as interleukin-10 (IL-10), transforming growth factor beta (TGF $\beta$ ), and vascular endothelial growth factor (VEGF). Anti-inflammatory macrophages stimulate ECM synthesis and scar formation [5].

Matrix metalloproteinase (MMP)-9 is a member of the MMP family of enzymes and is classified as a gelatinase for its ability to degrade denatured collagen. MMP-9 is robustly secreted by macrophages and degrades myocardial ECM to facilitate inflammatory cell infiltration, among other functions [6]. In the absence of MMP-9, macrophage infiltration into the infarct region is reduced, and remodeling of the left ventricle (LV) post-MI is attenuated [3, 7]. Therefore, we hypothesized that overexpression of human MMP-9 in mouse macrophages would amplify the inflammatory and fibrotic responses to exacerbate LV dysfunction. Accordingly, we examined the effect of transgenic overexpression of human MMP-9 in mouse macrophages after experimental MI, focusing on LV function, LV inflammatory gene expression, macrophage infiltration and phenotype, and LV ECM gene expression at day 5 post-MI.

\section{Materials and Methods}

\subsection{Mice}

All animal procedures were conducted according to the "Guide for the Care and Use of Laboratory Animals" (Eighth Edition, 2011, National Research Council) and were approved by the Institutional Animal Care and Use Committee at the University of Texas Health Science Center at San Antonio. The mice used in this study were male and female, 3-6 month old, WT littermates $(\mathrm{n}=16)$ and TG mice $(\mathrm{n}=34)$ overexpressing human MMP-9. Both groups had equal distribution of sex and equal average ages. TG mice carried the human MMP-9 cDNA ( $2.4 \mathrm{~kb})$ transgene driven by the scavenger receptor A enhancer/promoter $(4.5 \mathrm{~kb})$ as described previously [8]. MI was induced by surgical ligation of the left anterior descending (LAD) coronary artery, as described previously [3]. The copy number for the TG day 0 group was $3.8 \pm 1.0$ copies and for the day 5 TG MI group was $3.1 \pm 0.9$ copies. In the post-MI LV macrophages, total MMP- 9 gene expression increased $15 \pm 2$-fold compared to WT levels. 


\subsection{Echocardiography and Necropsy Evaluations}

Echocardiograms were acquired under spontaneous respiration with $0.5-2 \%$ isoflurane in a $100 \%$ oxygen mix. Electrocardiogram and heart rate were monitored throughout the imaging procedure using a surface electrocardiogram. All images were acquired with the use of a Vevo $770^{\mathrm{TM}}$ High-Resolution In Vivo Imaging System (Visual Sonics) and were taken at a heart rate $>400 \mathrm{bpm}$ to achieve physiologically relevant measurements. Measurements were taken from the two-dimensional parasternal long-axis and short axis (m-mode) recordings of the LV. For each parameter, 3 images from consecutive cardiac cycles were measured and averaged.

At 5 days post-MI, LV tissue was collected. The mice were anesthetized with $2 \%$ isoflurane, and the coronary vasculature was flushed with cardioplegic solution [9]. The hearts were excised and the LV and right ventricle were separated and weighed individually. The LV was sectioned into three transverse sections and stained with $1 \%$ 2, 3, 5 triphenyltetrazolium chloride (Sigma) for infarct area determination. The infarct (LVI) and remote (LVC) regions were separated, individually snap frozen, and stored at $-80^{\circ} \mathrm{C}$ for biochemical analysis. The mid section was fixed in zinc-formalin (Fisher Scientific), paraffin-embedded, and sectioned at $5 \mu \mathrm{m}$ for histological examination. The lungs were also removed and weighed. For controls, day 0 WT $(n=20)$ and TG $(n=19)$ mice were sacrificed as described above.

\subsection{Histological Evaluation}

Immunohistochemistry was performed with the use of the Vectastain ABC Kit (Vector Laboratories). HistoMark Black (KPL 54-75-00) was used to visualize positive staining, with eosin as a counterstain. An antibody specific for neutrophils (anti-neutrophil, mouse monoclonal from Cedarlane, \#CL8993AP; 1:100 dilution) was used to selectively detect neutrophils. Picrosirius red staining was used to visualize collagen content. Staining levels were quantified using Image-Pro software (Media Cybernetics) to calculate percentage of total area stained positive. Negative controls included no primary antibody and $\operatorname{IgG}$ isotype matched controls.

\subsection{Tissue Inflammatory and ECM Arrays}

LV tissue from WT and TG day 0 controls (3F/3M each for both groups) and WT and TG day 5 post-MI (3F/3M each for both groups) were collected. The infarct and remote regions from the post-MI mice were analyzed separately. RNA extraction was performed using Trizol ${ }^{\circledR}$ Reagent (Invitrogen 15596-026), and cDNA was synthesized using $\mathrm{RT}^{2}$ First Strand Kit (Qiagen 330401). The expression of inflammation and ECM genes was measured using the inflammatory cytokine and receptor array and the ECM and adhesion molecule array following the manufacturer recommendations (Qiagen PAMM-011 and PAMM-013, respectively). Gene expression was normalized to the hypoxanthine guanine phosphoribosyl transferase 1 (Hprt1) gene.

\subsection{Infarct Macrophage Isolations and qRT-PCR}

To isolate macrophages from 5 day LVI, we followed the preparation of single-cell suspension from the mouse heart protocol from Miltenyi Biotech, with slight modifications. Briefly, LVI tissue from WT $(n=4)$ and TG $(n=4)$ was minced and dissociated into singlecell suspension using collagenase II $(600 \mathrm{U} / \mathrm{mL}$, Worthington) and DNase I (60 U/mL, AppliChem) in Hanks' Balanced Salt Solution (HBSS, Gibco). After 45 min incubation at $37^{\circ} \mathrm{C}$, with mechanical dissociation applied every $15 \mathrm{~min}$, the cell suspension was centrifuged, resuspended in cold HBSS and applied over pre-separation filters to remove non-dissociated clumps (Miltenyi Biotec 130-041-407). The cells were pelleted by centrifugation at $300 \times \mathrm{g}$ for $10 \mathrm{~min}$ and resuspended in MACS separation buffer and Red 
Blood Cell Lysis Solution (Miltenyi Biotec). The cell suspension was purified using the mouse anti-LY-6G microbead kit (Miltenyi Biotec 130-092- 332) and applied over a magnetic MS column (Miltenyi Biotec 130-042-201) to remove neutrophils, which were not abundant at day 5 post-MI. The cells in the flow-through were resuspended in fresh separation buffer, and the macrophages were sorted using the mouse/human CD11b Microbead kit (Miltenyi Biotec 130-049-601). The CD11b positive cells were plated on Thermanox ${ }^{\circledR}$ coverslips or in a 24-well tissue culture plate and incubated in RPMI 1640 media (Gibco) supplemented with $10 \%$ fetal bovine serum. After overnight incubation, the adherent cells (i.e., macrophages) were washed using Hanks buffered saline solution, and were fixed with $4 \%$ paraformaldehyde (Sigma) for $25 \mathrm{~min}$ and stored in phosphate buffered saline at $4{ }^{\circ} \mathrm{C}$ for immunocytochemistry, or were collected for RNA isolation. RNA extraction was performed by lysing the cells directly in the well using RNeasy (Qiagen 12183- 018A), and cDNA was synthesized using High Capacity RNA to cDNA Kit (ABI 4387406). Quantitative real-time PCR (qRT-PCR) was performed using taqman gene expression assays (Applied Biosystems) for human MMP-9 (Hs00234579_m1) and mouse MMP-9 (Mm00442991_m1). For M1 macrophage activation, IL-1 $\beta$ (Mm01336189_m1), IL-6 (Mm00446190_m1), IFN- $\gamma$ (Mm01168134_m1), and TNFa (Mm00443258_m1) levels were assessed. For M2 macrophage activation, the levels of Arg1 (Mm00475988_m1), CD163 (Mm00474091_m1), mannose receptor 1 (Mm00485148_m1) and TGF $\beta 1$ (Mm01178820_m1) were measured. Gene expression was normalized to Gapdh (Mm99999915_g1).

\subsection{Peritoneal Macrophage Isolation and qRT-PCR}

Peritoneal macrophages were isolated from WT littermate $(n=3 F / 3 M)$ and TG $(n=3 F / 3 M)$ peritoneum, and $2 \times 10^{6}$ cells were plated on $25 \mathrm{~cm}^{2}$ cell culture flasks in RPMI 1640 media supplemented with $10 \%$ fetal bovine serum. After overnight incubation at $37^{\circ} \mathrm{C}$, the cells were serum starved for $24 \mathrm{~h}$ and treated using serum-free medium with and without LPS $(100 \mathrm{ng} / \mathrm{mL}$, Sigma) for $24 \mathrm{~h}$. The cells were washed with PBS and lysed directly in the plate, RNA was extracted, and expression of inflammatory cytokine and receptors were analyzed using the array described above.

\subsection{Protein Extraction and Immunoblotting}

Total protein was extracted from the day 0 controls, the LVC regions, and the LVI regions by homogenizing the sample with Sigma Reagent 4 (7 M urea, $2 \mathrm{M}$ thiourea, $40 \mathrm{mM}$ Trizma ${ }^{\circledR}$ base and the detergent $1 \% \mathrm{C} 7 \mathrm{BzO}$ ) and $1 \times$ Complete Protease Inhibitor Cocktail (Roche). Protein concentrations were determined using the Bradford assay (BioRad). Due to the high urea content in Reagent 4, protein extracts were diluted 1:40 with water for compatibility with Bradford assay reagents. Total protein $(10 \mu \mathrm{g})$ for each fraction of all samples were run on 26- well, 4-12\% criterion Bis-Tris gels (Bio-Rad), transferred onto nitrocellulose membranes (Bio- Rad) and stained with MemCode ${ }^{\mathrm{TM}}$ Reversible Protein Stain Kit (Pierce) to verify protein concentration and loading accuracy. Protein levels were quantified by immunoblotting using the following primary antibodies: alpha smooth muscle actin (Abcam ab5694), anti-human MMP-9 (Epitomics 1939-1), anti-mouse MMP-9 (Abcam ab38898), Mac 3 (Cedarlane CL8943AP), galectin 3 (R\&D AF1197), and vimentin (Abcam ab8545). Immunoblotting was performed as previously described [10]. Molecular Imaging Software (Kodak) and Image J were used to measure densitometry. Densitometric units were normalized to the densitometry of the total protein stain for the entire lane. The groups were sub-analyzed, to determine if there were any differences based on sex, for MMP-9, galectin-3, and Mac-3. There were no differences within the groups based on sex. Male and female results, therefore, were combined. 


\subsection{Statistical Analyses}

Data are reported as mean \pm SEM. Two group comparisons of untreated and treated cells were performed using paired t-tests. One-Way ANOVA followed by the Student NewmanKeuls post-hoc test was used for comparisons of more than two groups. A $p<0.05$ was considered significant.

\section{Results}

\subsection{5-Day post-MI Mortality}

During the 5 day post-MI protocol, WT mice had a mortality rate of $0 \%$ ( 0 of 16 mice), and TG mice had a mortality rate of $14.7 \%$ ( 5 of 34 mice; $p=0.16$ ). For the TG mortalities, 1 of the 5 deaths $(20 \%)$ was a confirmed cardiac rupture. Non-rupture related deaths, likely the result of acute heart failure or arrhythmias, accounted for $80 \%$ of the deaths (4 of 5 mice).

\subsection{Echocardiographic and Morphometric Analyses}

Echocardiographic, necropsy, and infarct size analyses for WT and TG mice at 5 days postMI are shown in Table 1. The control day 0 groups demonstrated no baseline differences in LV mass, right ventricle mass, lung mass or any of the echocardiographic parameters measured (all $\mathrm{p}=$ not significant).

In response to a similar extent of myocardial injury (average infarct size was $49 \%$ for WT and TG; $p=0.90$ ), both WT and TG day 5 post-MI groups had significant increases in end diastolic volume and significant decreases in posterior wall thickness when compared to controls (all p<0.05). Additionally, end systolic volume increased in both WT and TG animals post-MI, but the increase in end systolic volume of the TG was significantly attenuated compared to the WT group post-MI ( $<<0.05$ for day 5 WT vs TG).

Concomitantly, ejection fraction was also improved in the TG MI group compared to the WT MI group ( $\mathrm{p}<0.05$ ). In further support of improved LV function in the TG group, LV mass at necropsy did not increase post-MI in the TG mice, compared with the controls. In contrast, the WT post-MI LV showed significant increases in mass compared with day 0 controls $(\mathrm{p}<0.05)$.

\subsection{MMP-9 Protein Levels Post-MI}

After synthesis, most MMPs are secreted into the extracellular space as inactive enzymes containing an N-terminus pro-domain. Enzymatic cleavage of the pro-domain results in activation of the MMP [11]. Human pro-MMP-9 is a $92 \mathrm{kDa}$ protein, and active human MMP-9 has a relative mobility of $88 \mathrm{kDa}$, while mouse pro-MMP-9 is $105 \mathrm{kDa}$ and mouse active MMP-9 is $95 \mathrm{kDa}$. To verify expression of the transgene and activation of the human MMP-9 in our TG animals, we used an antibody specific for human MMP-9 (Epitomics 1939-1) for immunoblotting analysis. In the LVI protein extracts of the TG group (but not the WT), pro and active human MMP-9 were detected, indicating that expression of the transgene was responsive to MI, and the human MMP-9 could be activated from the proform (Figure 1A). To test whether the expression of the mouse MMP-9 was affected by the human TG, we used a mouse MMP-9 specific antibody (Abcam ab388898). Post-MI mouse MMP-9 protein levels in the LVI were similar in both WT and TG groups (Figure 1B, $\mathrm{p}=0.86$ ).

\subsection{Macrophage Infiltration}

To test if overexpression of MMP-9 increased macrophage infiltration, we used immunoblot analysis and antibodies for the macrophage markers galectin 3 (R\&D AF1197) and Mac-3 (Cedarlane CL8943AP). Surprisingly, galectin-3 (Figure 2A, p=0.78) and Mac-3 (Figure 2B, 
$\mathrm{p}=0.39$ ) protein concentrations were similar in the LVI of WT and TG groups post-MI, indicating that overexpression of human MMP-9 in macrophages did not affect macrophage infiltration at day 5 post-MI.

\subsection{Collagen Levels, Myofibroblasts, and Neutrophils}

To assess whether MMP-9 overexpression in macrophages had an effect on collagen accumulation at day 5 post-MI, the LVI of WT (Figure 3A) and TG (Figure 3B) were stained with picrosirius red. Collagen levels were similar in both groups at day 5 post-MI (Figure $3 \mathrm{C}, \mathrm{p}=0.11$ ). Concomitantly, the ratio of alpha smooth muscle actin and vimentin, as an indicator of myofibroblast levels, was also similar between the two groups $(\mathrm{p}=0.49)$. To quantify neutrophil numbers, we immunostained the LVI using an antibody specific for Ly-6G. Neutrophil numbers were similar in the LVI of WT and TG at day 5 post-MI (Figure $3 \mathrm{D} ; \mathrm{p}=0.14)$.

\subsection{Inflammatory Gene Arrays}

To test if MMP-9 overexpression in macrophages affects the inflammatory response postMI, we measured the inflammatory cytokine and receptor gene expression of both WT and TG day 0 controls, WT and TG day 5 post-MI remote (LVC), and WT and TG day 5 post$\mathrm{MI}$ infarct (LVI) regions (Figure $4, \mathrm{n}=6$ per group, $3 \mathrm{~F} / 3 \mathrm{M}$ ).

In the day 0 controls, expression of chemokine (CXC motif) ligand 12 (Cxcl12), a strong chemotactic molecule, was decreased in the TG MI compared to the WT MI, while interleukin 10 receptor beta (IL10rb) and small inducible cytokine subfamily E member 1 (Scye1) were increased in the TG MI compared to the WT MI (all p<0.05). None of the other 81 genes evaluated were different between the groups at day 0 .

Because macrophages concentrate in the infarct region, the majority of the inflammatory gene expression post-MI changes were, as expected, detected in the infarct region. Out of 84 genes examined, 21 genes were significantly differentially expressed in the WT LVI compared to WT control (Supplemental Table 1 and Figure 4; all p<0.05). In addition, 23 inflammatory genes were decreased in the TG LVI compared to the WT LVI (Figure 4; all $\mathrm{p}<0.05$ ). In the remote region ( $\mathrm{LVC}$ ), only the expression of Scye1 decreased in the TG mice compared to WT mice (Figure 4; $\mathrm{p}<0.05$ ). Interestingly, SPP1 and SCYE1 expression levels were significantly elevated in WT LVI compared to WT day 0 control, indicating strong macrophage activation in WT LV post-MI. Levels were significantly attenuated in the TG LVI compared to WT LVI. Pf4 is a strong chemoattractant for neutrophils and fibroblasts. In the inflammatory gene array panel, Pf4 gene expression levels were highly elevated in both WT LVC and LVI, and this elevation was significantly attenuated in TG LVC and LVI, suggesting blunted fibroblast activities, which may reduce scar formation. In addition, Cxcl12 was the most down-regulated gene in TG LVI, and Cxcl12 has been shown to play important roles in macrophage migration.

\subsection{Infarct Macrophage and Peritoneal Macrophage Gene Expression}

To further investigate the regulatory effects of MMP-9 overexpression post-MI, we isolated macrophages from WT $(n=4)$ and TG $(n=4)$ LVI tissue and measured gene expression levels of M1 and M2 activation markers. Representative images for WT (Figure 5A) and TG macrophages (Figure 5B) stained with anti-F4/80 (green) and Dapi (blue) qualitatively showed distinct phenotypes, in that the WT cells showed more robust staining for the F4/80 macrophage marker. To verify transgene activity in the isolated macrophages, we quantified the expression of the human MMP-9 transgene (Figure 5C). As expected, human MMP-9 was observed in TG macrophages but not WT macrophages. Interestingly, expression of the M1 activation markers IL- $1 \beta$ (Figure 5D) and TNFa (Figure 5E) were decreased $(\mathrm{p}<0.05)$ in 
the TG macrophages isolated from the LVI, indicating that MMP-9 overexpression served to dampen the proinflammatory response. Interestingly, the expression of other M1 activation markers (IL-6 and IFN- $\gamma$ ) and M2 activation markers (arginase 1, CD163, mannose receptor 1 and TGF $\beta 1$ ) were similar in both WT and TG macrophages isolated from the LVI at day 5 post-MI (all $\mathrm{p}=$ not significant). These results suggest that MMP-9 overexpression has specific regulatory effects on IL-1 $\beta$ and TNFa.

As a complement experiment, we used the inflammatory gene and receptor array to measure gene expression of peritoneal macrophages from WT $(n=6)$ and TG mice $(n=6)$ treated with LPS for $24 \mathrm{~h}$ (Supplemental Table 2). Of the 84 genes evaluated, 27 showed significant differences (Figure 6). Similar to the response observed in the LVI tissue and isolated LVI macrophages, reduced inflammatory gene expression (including IL-1 $\beta$ and TNFa ) was detected in the isolated TG peritoneal macrophages treated with LPS, compared to the WT macrophages treated with LPS.

\subsection{Extracellular Matrix Gene Arrays}

To measure the effects of a reduced inflammatory response on the ECM response post-MI, we measured the expression of $84 \mathrm{ECM}$ and adhesion molecules of matched WT and TG day 0 controls, WT and TG day 5 post-MI remote (LVC), and WT and TG day 5 post-MI infarct (LVI) regions (Supplemental Table 3 and Figure 7). In the day 0 controls, laminin beta 2 and MMP-15 were the only two genes altered in the TG LV and both were decreased in the TG compared to the WT controls $(\mathrm{p}<0.05)$.

Post-MI, gene expression levels of Cd44, ctnna1, itgb2, lama2, MMP-2, Sgce, and Vcam1 were all decreased in the TG LVC, compared to the WT LVC (all p<0.05). In line with a decreased inflammation in the infarct region, 43 of 84 ECM and adhesion genes decreased in the TG LVI compared to the WT LVI (all p<0.05). Interestingly, Adamts2, ECM1, fibronectin, TIMP-2, MMP-14, periostin, and tenascin were increased in the TG LVI compared to the WT LVI (all p<0.05), suggesting that these proteins may play an important role in the reparative process. Additionally, these results indicate that decreased inflammation dampened the fibrotic response post-MI.

\section{Discussion}

MMP-9 is a critical enzyme affiliated with post-MI remodeling [12]. In this study, we examined the effect of overexpression of human MMP-9 in mouse macrophages, with respect to left ventricular function, inflammatory gene and receptor expression, macrophage infiltration and activation, and ECM and adhesion molecule expression. The significant findings of this study were that MMP-9 overexpression in macrophages resulted in 1) improved left ventricular function, 2) reduced inflammatory responses in the LV infarct tissue and in isolated macrophages, and 3) decreased fibrotic responses at day 5 post-MI. These results suggest that MMP-9 regulates the inflammatory response to MI, which indirectly influences the fibrotic response.

Optimal infarct healing relies on the timely resolution of the inflammatory response. At the same time, macrophage depletion during the first week after MI results in defective myocardial healing $[13,14]$. Interestingly, the degree of macrophage activation and the heterogeneity of macrophage subsets regulate chemotaxis, phagocytosis of necrotic myocytes and apoptotic neutrophils, angiogenesis, ECM turnover, and fibroblast activation $[4,15]$.

MMP-9 is elevated early in the plasma and myocardium of post-MI patients and multiple animal models, and targeted deletion of MMP-9 in mice has been shown to protect against 
cardiac rupture and adverse ventricular remodeling post-MI [7, 16-18]. Because of the beneficial effects observed in the MMP-9 null mice post-MI, we predicted that transgenic overexpression of human MMP-9 in mouse macrophages would result in adverse remodeling and an increased incidence of rupture. At 5 day post-MI, however, survival was not affected by overexpression of MMP-9 in macrophages. Further, LV function was also improved.

Based on previous results with the MMP-9 null mice showing impaired macrophage infiltration at day 5 post-MI, we hypothesized that increased MMP-9 would stimulate macrophage infiltration and ECM degradation [3, 6]. Our results indicate that MMP-9 overexpression in macrophages did not affect macrophage infiltration. As neutrophils are another source of MMP-9, our results suggest that neutrophil-derived MMP-9 may play a more important role in macrophage migration than macrophage-derived MMP-9. Our results agree with previous literature using these mice in a model of asthma, where macrophage numbers that infiltrated into the lung were similar between WT and TG [19].

Our findings indicate that MMP-9 overexpression in macrophages reduces the expression of inflammatory genes and receptors in the LV infarct region post-MI. Moreover, MMP-9 overexpression regulated the inflammatory response of isolated macrophages from the LV infarct and LPS-stimulated peritoneal macrophages. It is important to mention that mRNA levels in isolated macrophages were evaluated after plating the cells, which could modify expression levels. As a consequence of reduced inflammation, the gene expression level of ECM and adhesion molecules was decreased in the TG mice post-MI. Of note, macrophage MMP-9 overexpression significantly decreased expression of mouse MMPs $-2,-3,-7,-8,-9$, $-10,-12$, and -13 , indicating that MMP-9 may be an important upstream mediator of these other MMPs. Interestingly, Adamts2, ECM1, fibronectin, MMP-14, periostin, tenascin, and TIMP-2 were upregulated in the TG compared to WT post-MI, indicating a beneficial role in cardiac wound healing at day 5 post-MI by stimulating a more robust scar formation. The fact that MMP-14 increased with MMP-9 overexpression suggests that MMP-14 may be upstream of MMP-9 or that MMP-14 may share a common pathway with MMP-9. Fibronectin expression during cardiac repair has been shown to serve as a scaffold for reparative ECM deposition and pluripotent cell migration [20-23]. In the post-MI setting, periostin null mice have been shown to have increased rupture rates as a result of decreased myocardial stiffness and collagen accumulation [24, 25]. Interestingly, tenascin C null animals have a phenotype similar to the seen in the TG mice; namely, attenuated LV remodeling post-MI [26]. Moreover, TIMP-2 null mice have severe inflammation and greater infarct expansion that exacerbated ventricular dilation [27]. These seven genes provide a targeted list for further studies into MMP-9 dependent mechanisms of LV remodeling.

Traditionally, MMP-9 is considered an enzyme that can degrade ECM; however, our findings indicate MMP-9 has a central role in the regulation of a multitude of cytokines and chemokines, including the pro-inflammatory genes IL- $1 \beta$ and TNFa. Consistent with our results, Cabrera and colleagues reported reduced pulmonary fibrosis in the bleomycin treated TG MMP- 9 mice that was due to increased MMP-9 activity and cleavage of the MMP-9 substrate insulinlike growth factor binding protein-3 [8]. Interestingly, in our inflammatory array, the gene expression of small inducible cytokine subfamily E, member 1 (SCYE1), a known MMP-9 substrate, was elevated at baseline and its expression decreased in both the LV remote and infarct regions of TG compared to the WT post-MI [28]. SCYE1, also known as EMAPII, is a proinflammatory cytokine whose expression is induced by apoptosis [29-31]. Although the mechanisms by which SCYE1 regulates inflammation are not well understood, our findings suggest that overexpression of MMP-9 may regulate the inflammatory response in part through SCYE1. 
In comparison to the MMP-9 null mice, which demonstrate reduced macrophage infiltration and collagen accumulation to improve LV function post-MI, our findings indicate that macrophage-overexpression of MMP-9 have a similar functional end product of reduced inflammation and fibrosis, albeit through different mechanisms.

In conclusion, this study demonstrated that human MMP-9 overexpression in mouse macrophages imparts a positive consequence on LV remodeling at day 5 post-MI. The MMP-9 transgenic mice showed improved left ventricular function and reduced inflammatory response with a concomitant decrease in ECM protein expression. Our data suggest that MMP-9 overexpression imparts a beneficial consequence in the setting of acute inflammation and post-MI remodeling.

\section{Supplementary Material}

Refer to Web version on PubMed Central for supplementary material.

\section{Acknowledgments}

We acknowledge support from T32 (HL07446), American Heart Association (09POST2150178), and HL075360S1 to RZ; NSF 0649172, NIH EB009496, and NIH 1SC2 HL101430 to Y-FJ; and from NHLBI HHSN 268201000036C (N01-HV-00244) for the San Antonio Cardiovascular Proteomics Center and R01 HL075360, the Max and Minnie Tomerlin Voelcker Fund, and the Veteran's Administration (Merit) to MLL.

\section{References}

1. Swirski FK, Nahrendorf M, Etzrodt M, Wildgruber M, Cortez-Retamozo V, Panizzi P, et al. Identification of splenic reservoir monocytes and their deployment to inflammatory sites. Science. 2009; 325:612-616. [PubMed: 19644120]

2. Nahrendorf M, Pittet MJ, Swirski FK. Monocytes: protagonists of infarct inflammation and repair after myocardial infarction. Circulation. 2010; 121:2437-2445. [PubMed: 20530020]

3. Lindsey ML, Escobar GP, Dobrucki LW, Goshorn DK, Bouges S, Mingoia JT, et al. Matrix metalloproteinase-9 gene deletion facilitates angiogenesis after myocardial infarction. Am J Physiol Heart Circ Physiol. 2006; 290:H232-H239. [PubMed: 16126817]

4. Lambert JM, Lopez EF, Lindsey ML. Macrophage roles following myocardial infarction. Int J Cardiol. 2008; 130:147-158. [PubMed: 18656272]

5. Ricardo SD, van Goor H, Eddy AA. Macrophage diversity in renal injury and repair. J Clin Invest. 2008; 118:3522-3530. [PubMed: 18982158]

6. Gong Y, Hart E, Shchurin A, Hoover-Plow J. Inflammatory macrophage migration requires MMP-9 activation by plasminogen in mice. J Clin Invest. 2008; 118:3012-3024. [PubMed: 18677407]

7. Ducharme A, Frantz S, Aikawa M, Rabkin E, Lindsey M, Rohde LE, et al. Targeted deletion of matrix metalloproteinase-9 attenuates left ventricular enlargement and collagen accumulation after experimental myocardial infarction. J Clin Invest. 2000; 106:55-62. [PubMed: 10880048]

8. Cabrera S, Gaxiola M, Arreola JL, Ramirez R, Jara P, D'Armiento J, et al. Overexpression of MMP9 in macrophages attenuates pulmonary fibrosis induced by bleomycin. Int J Biochem Cell Biol. 2007; 39:2324-2338. [PubMed: 17702637]

9. Lindsey ML, Escobar GP, Dobrucki LW, Goshorn DK, Bouges S, Mingoia JT, et al. Matrix metalloproteinase-9 gene deletion facilitates angiogenesis after myocardial infarction. Am J Physiol Heart Circ Physiol. 2006; 290:H232-H239. [PubMed: 16126817]

10. Zamilpa R, Lopez EF, Chiao YA, Dai Q, Escobar GP, Hakala K, et al. Proteomic Analysis Identifies In vivo Candidate Matrix Metalloproteinase-9 Substrates in the Left Ventricle PostMyocardial Infarction. Proteomics. 2010; 10:2214-2223. [PubMed: 20354994]

11. Nagase H. Activation mechanisms of matrix metalloproteinases. Biol Chem. 1997; 378:151-160. [PubMed: 9165065] 
12. Lindsey ML, Zamilpa R. Temporal and spatial expression of matrix metalloproteinases and tissue inhibitors of metalloproteinases following myocardial infarction. Cardiovascular therapeutics. 2012; 30:31-41. [PubMed: 20645986]

13. Tao ZY, Cavasin MA, Yang F, Liu YH, Yang XP. Temporal changes in matrix metalloproteinase expression and inflammatory response associated with cardiac rupture after myocardial infarction in mice. Life Sci. 2004; 74:1561-1572. [PubMed: 14729404]

14. van Amerongen MJ, Harmsen MC, van Rooijen N, Petersen AH, van Luyn MJ. Macrophage depletion impairs wound healing and increases left ventricular remodeling after myocardial injury in mice. Am J Pathol. 2007; 170:818-829. [PubMed: 17322368]

15. Zamilpa R, Kanakia R, Cigarroa Jt, Dai Q, Escobar GP, Martinez H, et al. CC chemokine receptor 5 deletion impairs macrophage activation and induces adverse remodeling following myocardial infarction. Am J Physiol Heart Circ Physiol. 2011; 300:H1418-H1426. [PubMed: 21297029]

16. Heymans S, Luttun A, Nuyens D, Theilmeier G, Creemers E, Moons L, et al. Inhibition of plasminogen activators or matrix metalloproteinases prevents cardiac rupture but impairs therapeutic angiogenesis and causes cardiac failure. Nat Med. 1999; 5:1135-1142. [PubMed: 10502816]

17. Kelly D, Cockerill G, Ng LL, Thompson M, Khan S, Samani NJ, et al. Plasma matrix metalloproteinase- 9 and left ventricular remodelling after acute myocardial infarction in man: a prospective cohort study. Eur Heart J. 2007; 28:711-718. [PubMed: 17339265]

18. Sundstrom J, Evans JC, Benjamin EJ, Levy D, Larson MG, Sawyer DB, et al. Relations of plasma matrix metalloproteinase-9 to clinical cardiovascular risk factors and echocardiographic left ventricular measures: the Framingham Heart Study. Circulation. 2004; 109:2850-2856. [PubMed: 15173025]

19. Mehra D, Sternberg DI, Jia Y, Canfield S, Lemaitre V, Nkyimbeng T, et al. Altered lymphocyte trafficking and diminished airway reactivity in transgenic mice expressing human MMP-9 in a mouse model of asthma. Am J Physiol Lung Cell Mol Physiol. 2010; 298:L189-L196. [PubMed: 19940022]

20. van Dijk A, Niessen HW, Ursem W, Twisk JW, Visser FC, van Milligen FJ. Accumulation of fibronectin in the heart after myocardial infarction: a putative stimulator of adhesion and proliferation of adipose-derived stem cells. Cell Tissue Res. 2008; 332:289-298. [PubMed: 18305959]

21. Ulrich MM, Janssen AM, Daemen MJ, Rappaport L, Samuel JL, Contard F, et al. Increased expression of fibronectin isoforms after myocardial infarction in rats. J Mol Cell Cardiol. 1997; 29:2533-2543. [PubMed: 9299376]

22. Willems IE, Arends JW, Daemen MJ. Tenascin and fibronectin expression in healing human myocardial scars. J Pathol. 1996; 179:321-325. [PubMed: 8774490]

23. Cleutjens JP, Verluyten MJ, Smiths JF, Daemen MJ. Collagen remodeling after myocardial infarction in the rat heart. Am J Pathol. 1995; 147:325-338. [PubMed: 7639329]

24. Shimazaki M, Nakamura K, Kii I, Kashima T, Amizuka N, Li M, et al. Periostin is essential for cardiac healing after acute myocardial infarction. J Exp Med. 2008; 205:295-303. [PubMed: 18208976]

25. Kuhn B, del Monte F, Hajjar RJ, Chang YS, Lebeche D, Arab S, et al. Periostin induces proliferation of differentiated cardiomyocytes and promotes cardiac repair. Nat Med. 2007; 13:962-969. [PubMed: 17632525]

26. Nishioka T, Onishi K, Shimojo N, Nagano Y, Matsusaka H, Ikeuchi M, et al. Tenascin-C may aggravate left ventricular remodeling and function after myocardial infarction in mice. American journal of physiology. 2010; 298:H1072-H1078. [PubMed: 20081106]

27. Kandalam V, Basu R, Abraham T, Wang X, Soloway PD, Jaworski DM, et al. TIMP2 deficiency accelerates adverse post-myocardial infarction remodeling because of enhanced MT1-MMP activity despite lack of MMP2 activation. Circ Res. 2010; 106:796-808. [PubMed: 20056917]

28. Liu J, Schwarz MA. Identification of protease-sensitive sites in Human Endothelial-Monocyte Activating Polypeptide II protein. Exp Cell Res. 2006; 312:2231-2237. [PubMed: 16674941] 
29. Yao C, Williams AJ, Ottens AK, Lu XC, Liu MC, Hayes RL, et al. P43/pro-EMAPII: a potential biomarker for discriminating traumatic versus ischemic brain injury. J Neurotrauma. 2009; 26:1295-1305. [PubMed: 19317603]

30. Thompson JL, Ryan JA, Barr ML, Franc B, Starnes VA, Schwarz MA. Potential role for antiangiogenic proteins in the myocardial infarction repair process. J Surg Res. 2004; 116:156164. [PubMed: 14732363]

31. Kayton ML, Libutti SK. Endothelial monocyte activating polypeptide II (EMAP II) enhances the effect of TNF on tumor-associated vasculature. Curr Opin Investig Drugs. 2001; 2:136-138. 


\section{A. Human MMP-9 \\ WT}
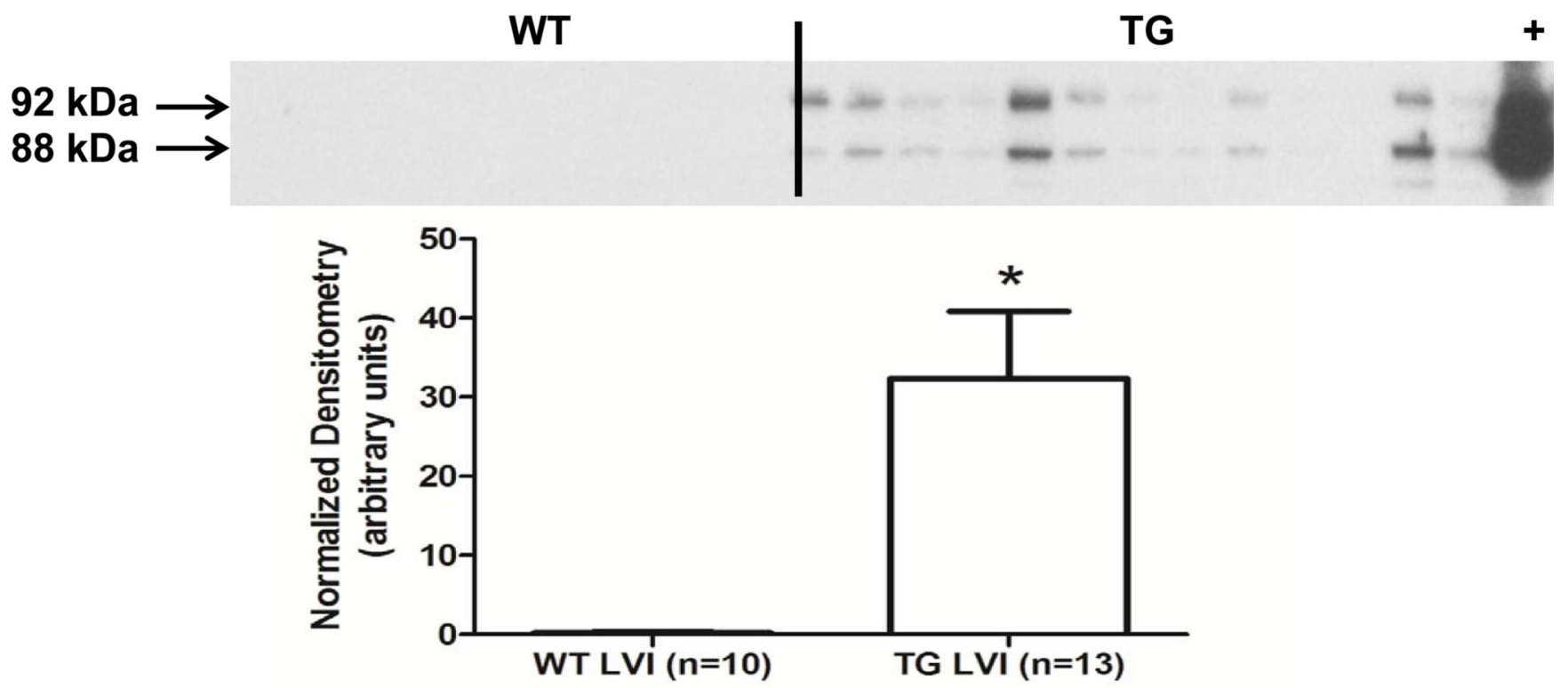

B. Mouse MMP-9

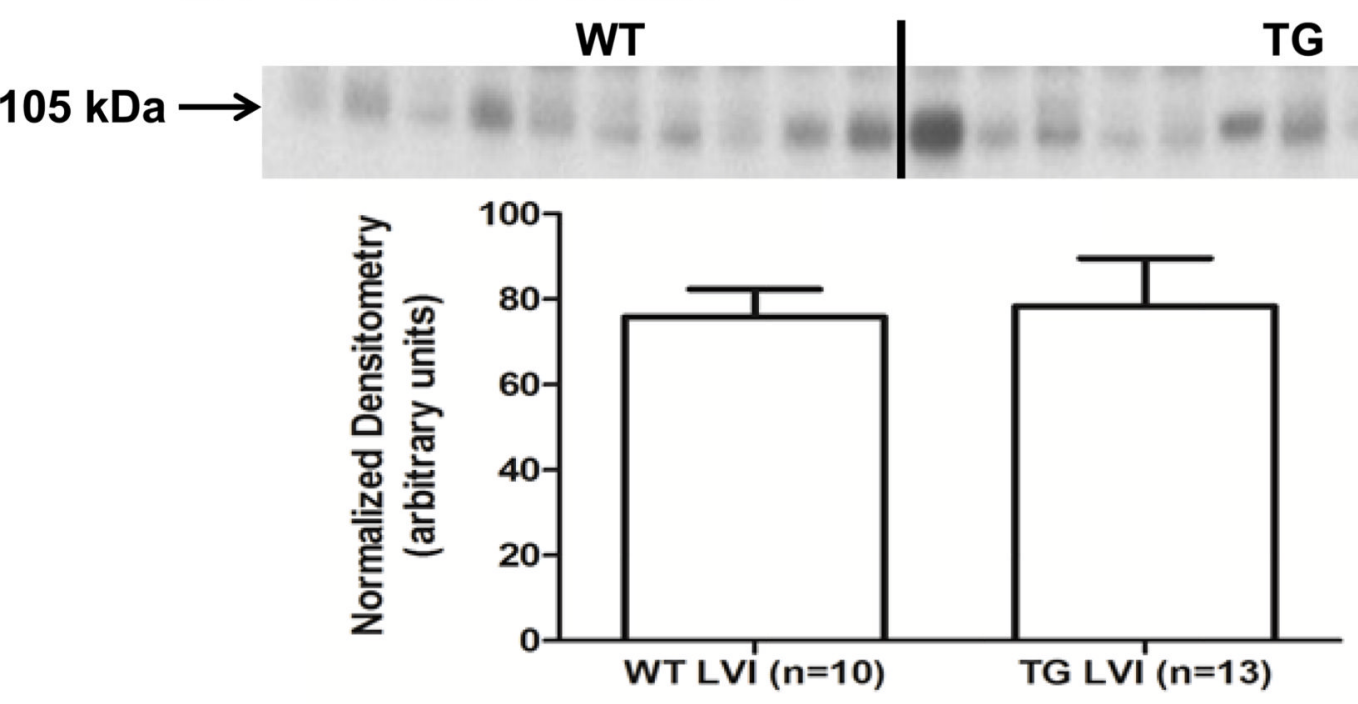

Figure 1.

Human MMP-9 levels increased in the TG LVI. (A) Human pro (92 kDa) and active MMP-9 $(88 \mathrm{kDa})$ increased in the LVI of TG mice at day 5 post-MI. + is the human macrophage extract positive control for human MMP-9 (B) Mouse MMP-9 (105 kDa) levels were not changed in response to activity of the human transgene. + is mouse spleen extract used as a positive control for mouse MMP-9. Sample sizes are $n=10$ for WT LVI and $n=13$ for TG LVI; * $\mathrm{p}<0.05$ for human MMP-9; and $\mathrm{p}=0.86$ for mouse MMP-9. 


\section{A. Galectin-3}
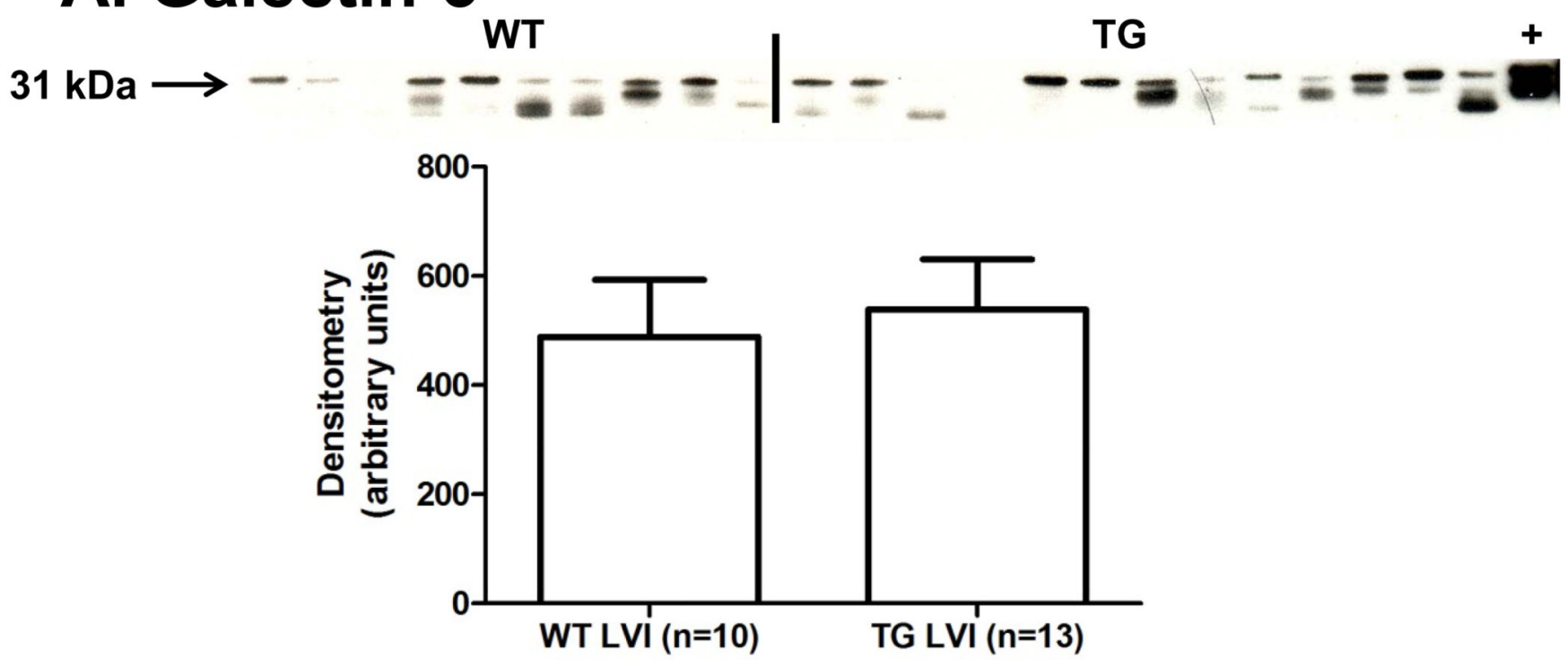

\section{B. Mac-3}

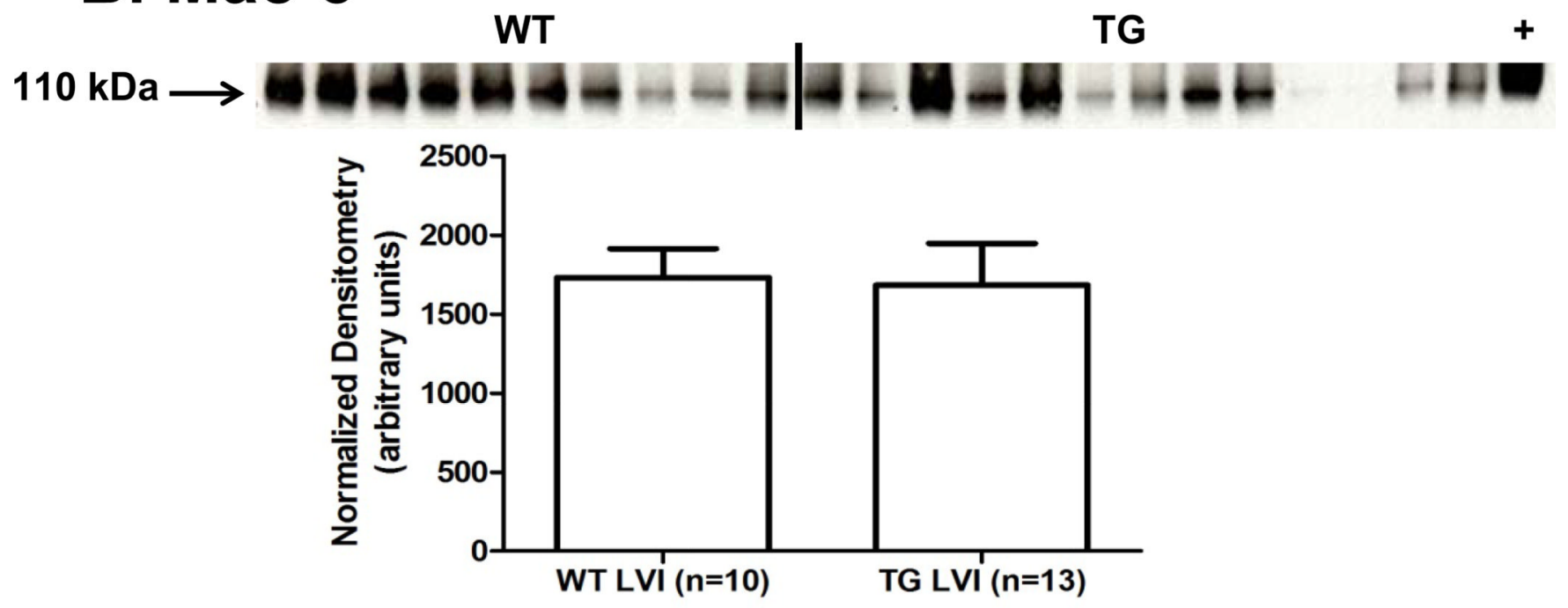

Figure 2.

Macrophage numbers were similar in WT and TG mice at day 5 post-MI. (A) Galectin- 3 (B) Mac-3 protein levels were similar in the LV infarct at day 5 post-MI. LVI-infarct region; + is spleen extract positive control. Sample sizes are $n=10$ for WT LVI and $n=13$ for TG LVI; $\mathrm{p}=0.78$ for Galectin -3 and $\mathrm{p}=0.39$ for Mac-3. 


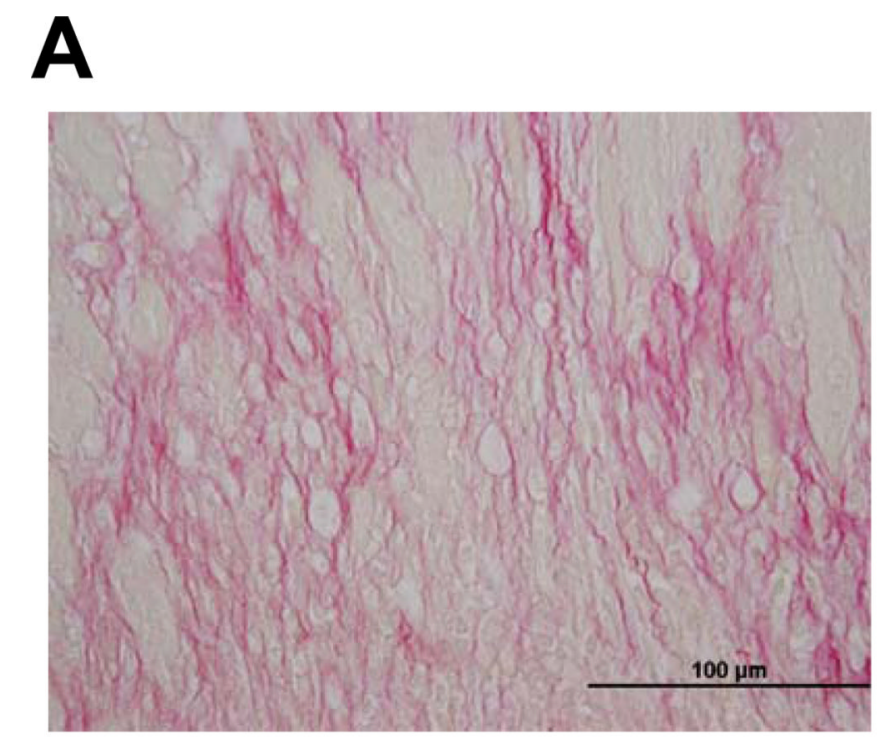

\section{B}
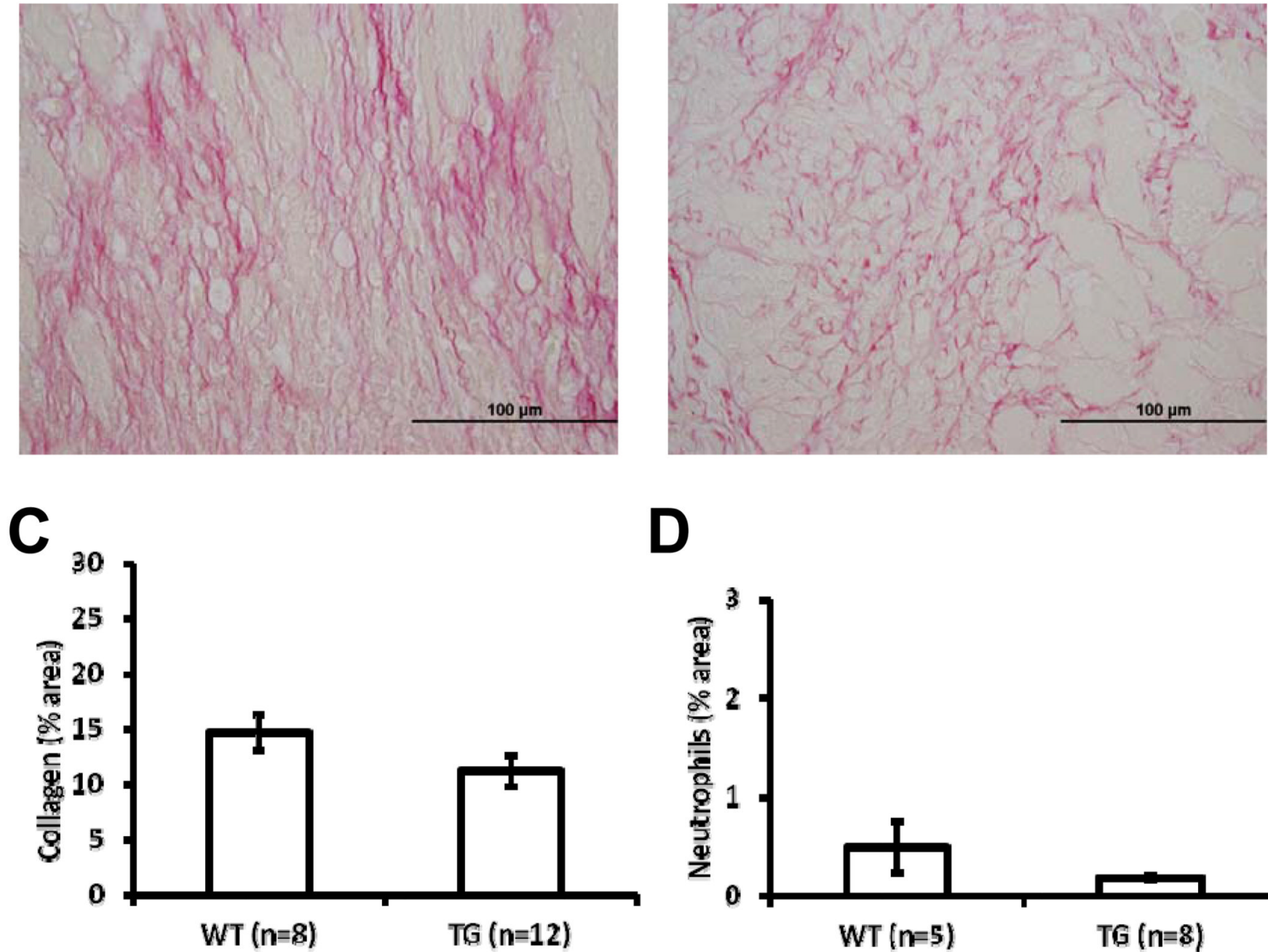

Figure 3.

Collagen levels and neutrophils were similar in WT and TG mice at day 5 post-MI. Midventricular, transverse sections of the WT LVI (A) and TG LVI (B) stained with picrosirius red indicated no difference in collagen content at day 5 post-MI $(\mathrm{C}, \mathrm{p}=0.11)$.

Immunostaining using an anti-neutrophil antibody indicated similar number of neutrophils in both groups at day 5 post-MI (D, p=0.14). 


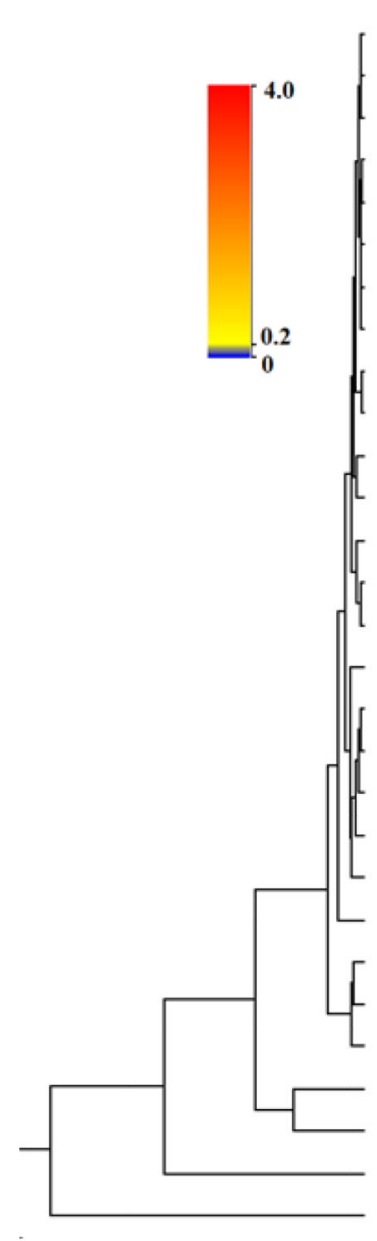

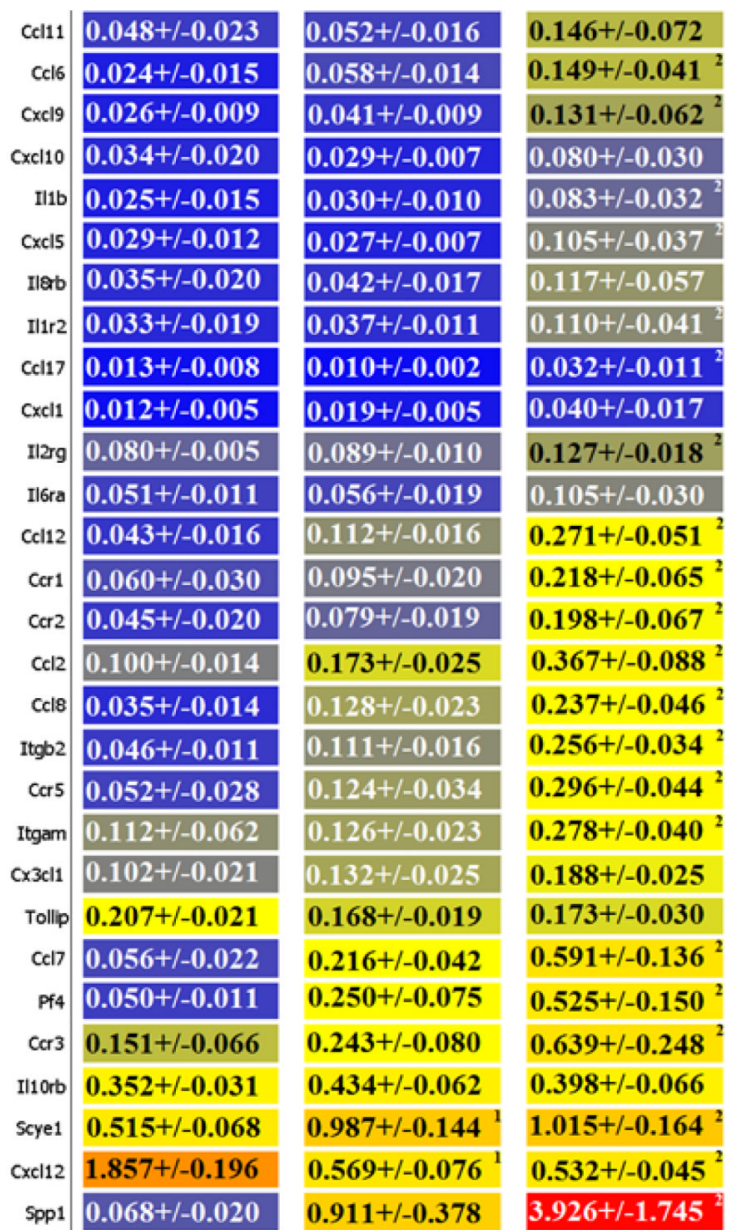

WT
WT LVC
WT LVI

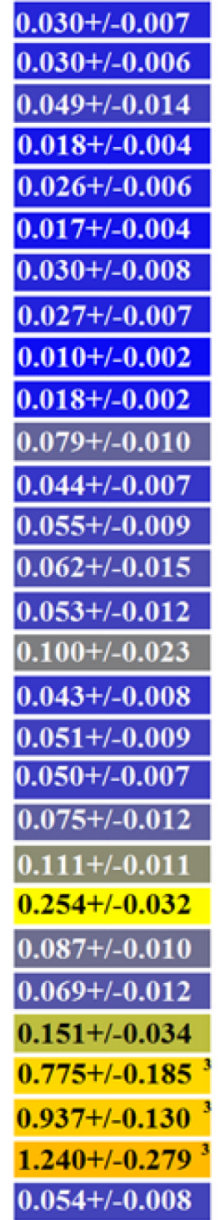

TG
$0.008+/-0.002$

$0.009+/-0.003$

$0.006+/-0.001$

$0.008+/-0.002$

$0.008+/-0.002$

$0.004+/-0.000$

$0.004+/-0.000$

$0.007+/-0.002$

$0.003+/-0.000$

$0.003+/-0.000$

$0.066+/-0.007$

$0.074+/-0.012$

$0.020+/-0.009$

$0.034+/-0.006$

$0.026+/-0.011$

$0.115+/-0.017$

$0.047+/-0.018$

$0.051+/-0.015$

$0.047+/-0.021$

$0.084+/-0.016$

$0.106+/-0.022$

$0.149+/-0.012$

$0.039+/-0.023$

$0.066+/-0.015$

$0.031+/-0.013$

$0.451+/-0.043$

$0.459+/-0.029$

$0.935+/-0.089$

$0.330+/-0.169$

TG LVC

\begin{tabular}{|l|}
\hline $0.004+/-0.001$ \\
\hline $0.015+/-0.007$ \\
\hline $0.006+/-0.002$ \\
\hline $0.012+/-0.003$ \\
\hline $0.009+/-0.003$ \\
\hline $0.009+/-0.003^{3}$ \\
\hline $0.005+/-0.001^{3}$ \\
\hline $0.030+/-0.010^{5}$ \\
\hline $0.009+/-0.001^{3}$ \\
\hline $0.005+/-0.000^{3}$ \\
\hline $0.075+/-0.010^{5}$ \\
\hline $0.122+/-0.016^{2}$ \\
\hline $0.057+/-0.022$ \\
\hline $0.051+/-0.012$ \\
\hline $0.060+/-0.022^{5}$ \\
\hline $0.101+/-0.014^{5}$ \\
\hline $0.152+/-0.063$ \\
\hline $0.166+/-0.043^{2}$ \\
\hline $0.182+/-0.048$ \\
\hline $0.216+/-0.030^{5}$ \\
\hline $0.246+/-0.049^{2}$ \\
\hline $0.119+/-0.012^{3}$ \\
\hline $0.056+/-0.021$ \\
\hline $0.130+/-0.030^{5}$ \\
\hline $0.084+/-0.031^{5}$ \\
\hline $0.559+/-0.108$ \\
\hline $0.519+/-0.079$ \\
\hline $0.980+/-0.100$ \\
\hline $1.196+/-0.315^{5}$ \\
\hline TG L L \\
\hline
\end{tabular}

Figure 4.

Expression of inflammatory cytokine and receptor genes were decreased in the left ventricle infarct (LVI) post-MI of TG compared to WT mice. The expression of 84 cytokine and receptor genes were quantified in the wild type (WT) and transgenic (TG) day 0 controls and in the WT remote region (WT LVC), WT infarct region (WT LVI), TG remote (TG LVC), and TG infarct (TG LVI) at day 5 post-MI. By ANOVA, $\mathrm{p}<0.05$ for 1 -WT vs WT LVC or TG vs TG LVC; 2-WT vs WT LVI or TG vs TG LVI; 3-WT vs TG; 4-WT LVC vs TG LVC; and 5-WT LVI vs TG LVI. 


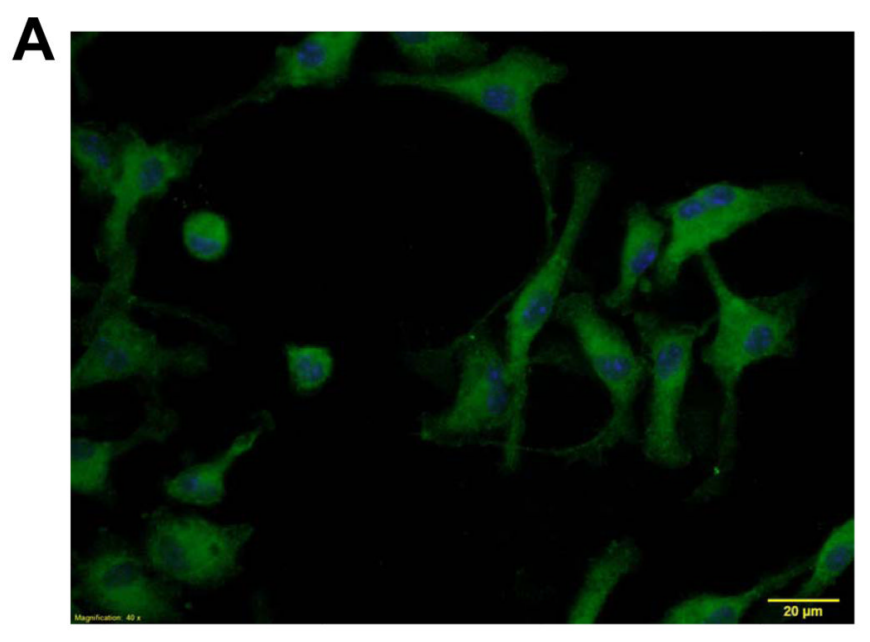

C

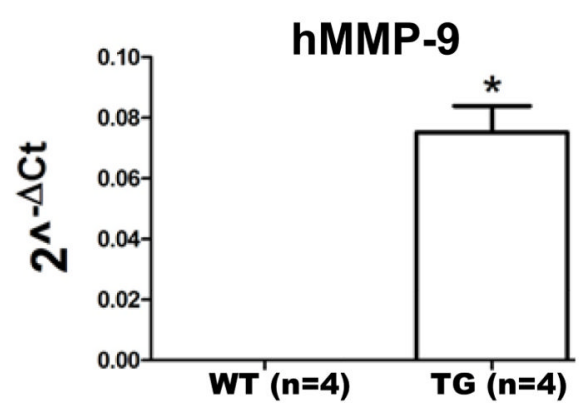

B

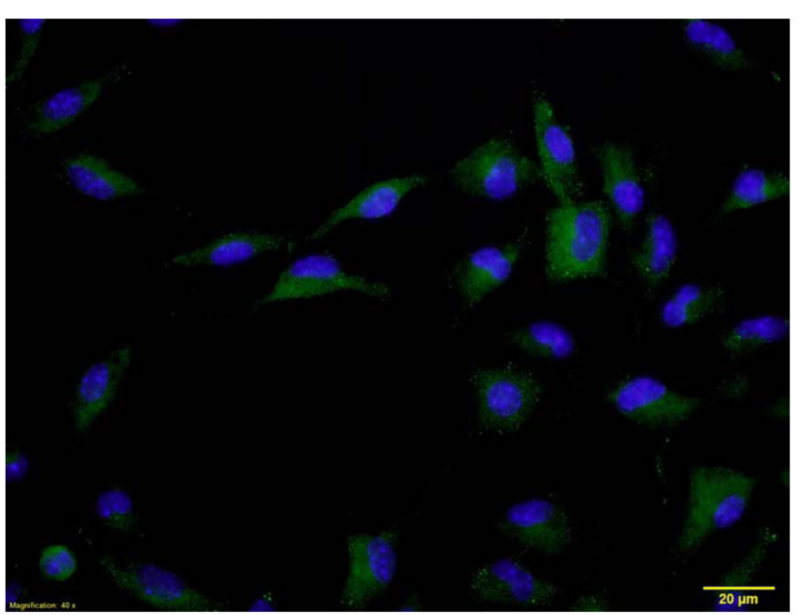

$\mathbf{E}$
D

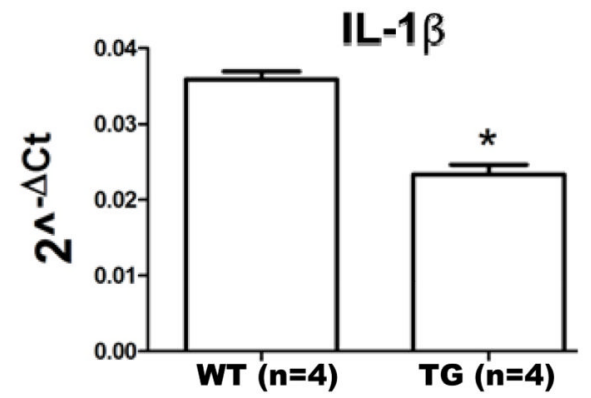

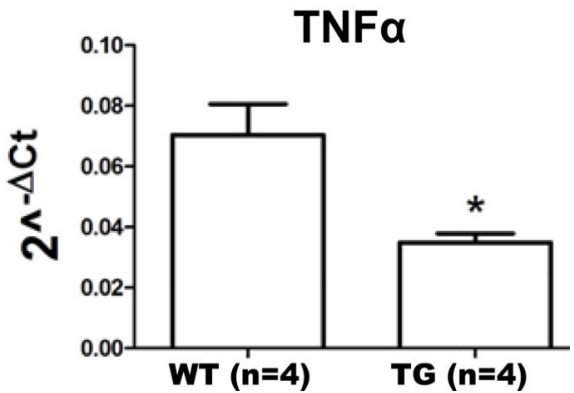

Figure 5.

Macrophages isolated from the infarct region of TG mice at day 5 post-MI have reduced expression of pro-inflammatory markers IL- $1 \beta$ and TNFa compared to WT post-MI LV. (A) WT macrophages and (B) TG macrophages isolated from the LVI stained with F4/80 (green) and Dapi (blue). Scale bar is $20 \mu \mathrm{m}$. (C) Human MMP-9 (hMMP-9) was expressed in macrophage isolated from the LV infarct at day 5 post-MI in TG but not WT mice. (D) IL-1 $\beta$ and (E) TNFa levels were significantly decreased in TG macrophages compared to WT macrophages. Sample sizes are $n=4$ for both groups, ${ }^{*} \mathrm{p}<0.05$ vs WT LVI macrophages. 


\section{9}

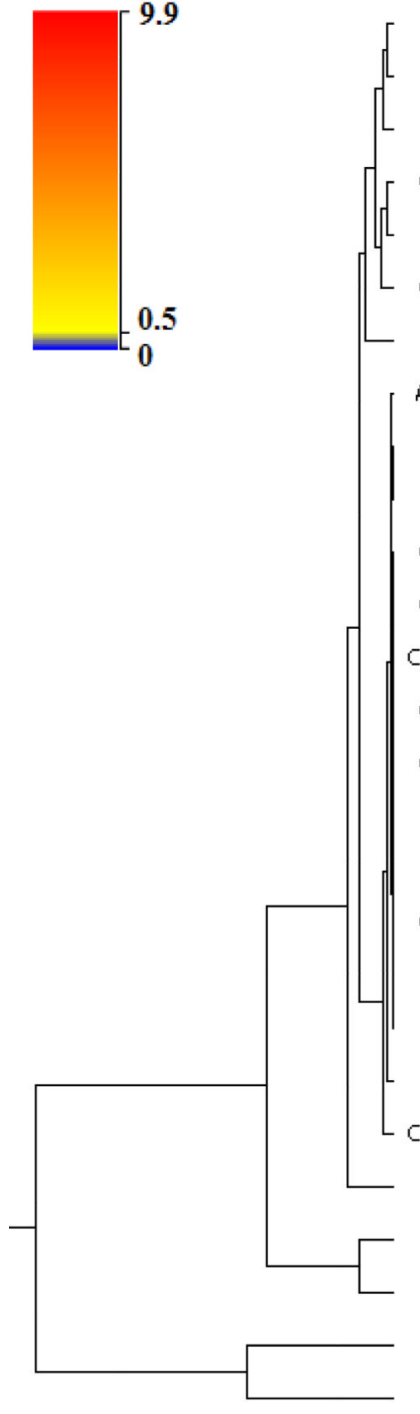

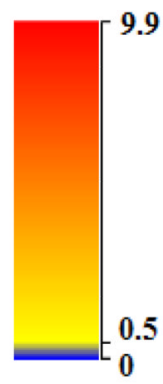
.5

Ccl2 $\mathbf{0 . 0 5 9 7 + / - 0 . 0 2 4 0}$

Ccl7 $\mathbf{0 . 0 3 0 1 + / - 0 . 0 1 2 1}$

1

$0730+/-0.3134$

$0.9730+/-0.3431$

Col4 $\mathbf{0 . 0 6 9 8 + / - 0 . 0 2 0 0}$

$0.8106+/-0.3093$

Cxal $0.0416+/-0.0175$

$0.5749+/-0.1331$

Tnf $\mathbf{0 . 0 9 3 7 + / - 0 . 0 3 6 0}$

Cxcl5 $\mathbf{0 . 0 0 9 9 + / - 0 . 0 0 4 0}$

$0.4455+/-0.0986$

Mif $0.4632+/-0.1025$

$0.7935+/-0.5847$

bucfi $\mathbf{0 . 0 3 7 4 + / - 0 . 0 1 0 9}$

$1.2499+/-0.2068$

Car3 $0.0614+/-0.0236$

$0.0556+/-0.0121$

Car5 $\mathbf{0 . 0 5 9 3 + / - 0 . 0 1 6 9}$

Ccl22 $\mathbf{0 . 0 0 1 8 + / - 0 . 0 0 1 0}$

$0.0413+/-0.0280$

$0.0347+/-0.0222$

ccl17 $\mathbf{0 . 0 0 1 3}+/ \mathbf{0 . 0 0 1 0}$

$0.0047+/-0.0012$

Cxcl12 $\mathbf{0 . 0 0 1 9 + / - 0 . 0 0 1 0}$ $0.0048+/-0.0017$

$c c 12 \quad \mathbf{0 . 0 0 1 5}+/-\mathbf{0 . 0 0 1 0}$

$0.0019+/-0.0005$

$0.0029+/-0.0008$

Cxcl9 $\mathbf{0 . 0 0 1 6 + / - 0 . 0 0 1 0}$

$0.0031+/-0.0008$

ccr2 $\mathbf{0 . 0 0 1 7 + / - 0 . 0 0 1 0}$

$0.0024+/-0.0007$

Ccr9 $\mathbf{0 . 0 0 1 9 + / - 0 . 0 0 1 0}$

$0.0026+/-0.0006$

$c_{c l 19} \mathbf{0 . 0 0 3 7 + / - 0 . 0 0 1 1}$

$0.0099+/-0.0032$

Bicls $\mathbf{0 . 0 3 7 6 + / - 0 . 0 1 8 4}$

$0.0057+/-0.0019$

IlGra $\mathbf{0 . 0 3 0 4 + / - 0 . 0 1 3 8}$

$0.0089+/-0.0036$

Cols $0.1301+/-0.0355$

$0.0596+/-0.0333$

Cxl10 $0.0046+/-0.0019$

$0.3120+/-0.1907$

a $0.0414+/-0.0141$

a.0367+/-0.0189

a $0.0425+/-0.0124$

a $0.0169+/-0.0083$

a 0.0

$0.0340+/-0.0077$

$0.0064+/-0.0027$

a 0 .

$0.4420+/-0.0775$

$0.0311+/-0.0052$

Spp1 $0.9886+/-0.7057$

$0.5257+/-0.4009$

Cd3 $0.2658+/-0.0850$

$2.8819+/-0.8445$

Col5 $0.2128+/-0.1170$

$3.8322+/-0.9949$

$0.0781+/-0.0217$

$0.0921+/-0.0205$

$0.0008+/-0.0003$

$0.0004+/-0.0001$

$0.0016+/-0.0005$

$0.0006+/-0.0002$

$0.0007+/-0.0003$

$0.0006+/-0.0002$

$0.0007+/-0.0002$

$0.0029+/-0.0010$

$0.0248+/-0.0078$

$0.0185+/-0.0049$

$0.1682+/-0.0492$

$0.0009+/-0.0002$

$0.6803+/-0.2616$

$0.4892+/-0.1878$

$0.8093+/-0.2780$

$0.4064+/-0.0785$ a

$0.3031+/-0.0509$

$0.1715+/-0.0657$

$0.7152+/-0.2101$

Il1a $0.3992+/-0.1548$

$6.8925+/-1.7497$

$0.8587+/-0.2733$

$0.0352+/-0.0098$

Ilib $0.5032+/-0.2239$

$9.8563+/-3.2366$

$0.1422+/-0.0306$

$0.0198+/-0.0041$

$0.0166+/-0.0034$

$0.0225+/-0.0030$

$0.0039+/-0.0016$

$0.0030+/-0.0010$

$0.0003+/-0.0001$

$0.0006+/-0.0002$

$0.0005+/-0.0002$

$0.0004+/-0.0002$

$0.0006+/-0.0001$

$0.0012+/-0.0006$

WT

WT+LPS

TG

$0.0054+/-0.0022$

$0.0062+/-0.0026$

$0.0445+/-0.0165$

$0.0187+/-0.0087$

$0.2993+/-0.1316$

$1.9390+/-0.5172$

$1.9307+/-0.5557$ 1,2

$5.1271+/-1.3288$

$0.1316+/-0.0372$

$7.9342+/-2.4831$

TG+LPS

Figure 6.

TG peritoneal macrophages have decreased gene expression of inflammatory cytokine and receptors after treatment with LPS. We quantified the expression of 84 inflammatory cytokine and receptor genes of untreated WT and TG peritoneal macrophages and LPStreated WT (WT+LPS) and transgenic peritoneal macrophages (TG+LPS). By paired t-test, $\mathrm{p}<0.05$ for a-WT vs WT+LPS or TG vs TG+LPS; and by ANOVA, $\mathrm{p}<0.05$ for 1-WT vs WT +LPS or TG vs TG+LPS and 2-WT+LPS vs TG+LPS. 


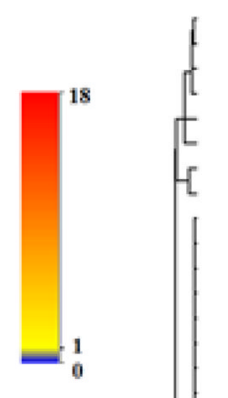

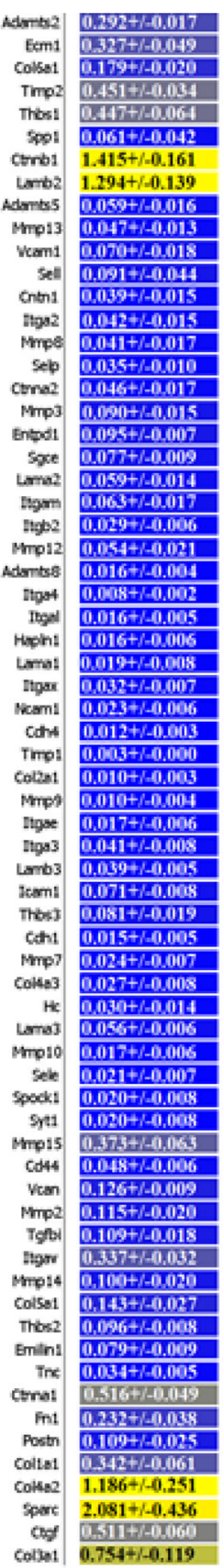

wT

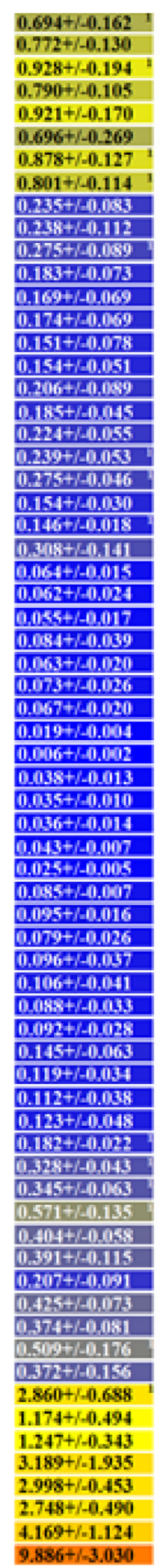

WT LVC
$0.875+<-0.115$ : $0.851+/-0.162$ $0.864+-0.104$ $1.635+-0.215$ $1.635+-0.215$ $0.838+/-0.141$ $0.515+150.125$ $0,0.375+120,157$ $0.377+180.167$ $0.373+1.0 .074$ D.jintil-0.166 $0.290+10.130$ $0.377+20.144$ $0.33+7.0 .140$ 0.1 .33 $\frac{0.118+2.115}{0.101+2.0 .112}$ $\frac{0.101+2.0112}{0.352+20.113}$ $\frac{0.352+120.113}{0.324+/ 20092}$

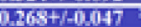
$0.316+2-0.045$

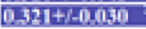

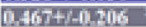
$0.115+1-0.042$ $0.07+400044$ 0.19+ +R0017 $0.146+20003$ 0.145+/20064 0.153+L0055 $0.134+20.043$ $0.037+20.015$ $0.014+/ 20.0006$ $0.050+200035$ $0.052+20.019$ $006 s+l-00020$ $0061+20.018$

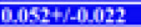
$0.124+100.023$ $0.136+1-0.026$ $0.203+20.0059$ $0.27+20.102$ $0.189+20.055$ 0.175+20075 $0.185+[20.077$ $0.202+/-0.095$ $0.258+20.102$ $0.261+/ 20.118$ $0.248+20.113$ $0.159+200045$ $0.568+2-0.0157$ $\frac{0.214+i-0.951}{0.681+/-0.172}$ $0.681+/-0.172$ $0.792+1-0.210$ $0.562+1-0.065$ $0.731+1-0.171$ $0.790+/-0.133$ $\frac{0.790+7-0.133}{0.556+1.0 .136}$ $0.556+100.156$ $2.094+/-0.484$ $2.025+1-0.510$ $1.791+/-0.437$ $4.335+/-1.142$ $3.108+/-0.752$ $4.993+l-1.629$ $6.532+/=2.176$

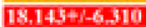

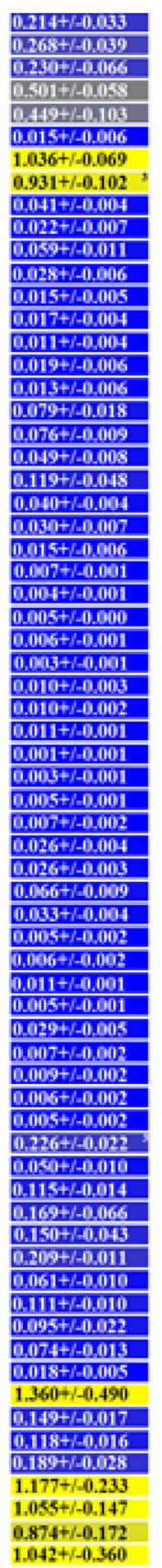

$0.563+/-0.097$ $0.651+/-0.090$ $0.517+7-0.145$ $0.625+/-0.075$ $0.863+/-0.258$ $0.381+-0.207$ $0.932+/-0.054$

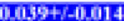
$0.005+i-10.001$ $0.003+c 0.003$ $0.013+/ .0002$ $0.003+/ 20.001$ $0.006+7.0002$ $0.0015+120.002$ $0.021+7-0.005$ $0.002+2-0.000$ $0.071+30005$ $0.122+/ 20.055$ $0.065+2.0 .011$ $0.059+/ 40.011$ $0.004+70.018$ $0.051+7.0017$ $0.002+20.000$ $0.02+\%+0.009$ $0.004+>0001$ 0.0.5R+R-0.0.04 $0.002+1-0.000$ $0.003+2-0.00$ $0,021+2-0,0.5$ $0.031+1-0.010$ $0.007+2-0.0 .01$ $\frac{0.001+\lambda 0.000}{0.002+3-0.000}$ $0.003+20001$ $0.006+[20.0 .01$ $\frac{0.006+2-0.0 .01}{0.026+20.003}$ $0.024+1-0.0013$ $0.067+20.010$ $0.065+100011$ 0007+ + -10000 $0.002+\angle 0.000$ $0.000+1-10.001$ $0.002+2.0000$ $\frac{0.002+210004}{0.026+\ln 0005}$ $0.002+2-0.000$ $0.009+/-0.003$ $0.002+1.0000$ $\frac{0.002+i c 0.000}{0.79 z+1.005}$ $\frac{0.148+[-0.0402}{0.15}$ $\frac{0.14 k+1-10.040}{0.215+1.0022}$ $0.198+20.045$ 0.2544+20.044 $0.158+\pi 001$ 0.574+r-1009: $\frac{0.574+2-102 k}{0.252+2-0.083}$ $\frac{0.252+\lambda-10083}{0.301+r-0.070}$ $0.001+1-0.070$ $1.057+/-0.242$ $0.996+1-0.358$ $0.754+/-0.253$ $2.762+1-1.156$ $2.180+/-0.410$ $2.150+/-0.410$
$2.517+1-0.74 ?$ $2.059+1-0.685$ $4.368+1-1.797$

TGLVC

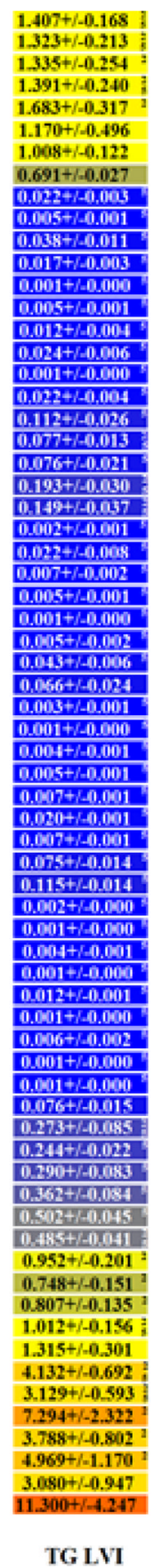

Figure 7.

Expression of ECM and adhesion molecule genes are decreased in the TG mice left ventricle infarct (LVI) at day 5 post-MI compared to WT LVI. The expression of 84 ECM molecule and adhesion genes were quantified in the wild type (WT) and transgenic (TG) day 0 controls and in the WT remote region (WT LVC), WT infarct region (WT LVI), TG remote region (TG LVC) and TG infarct region (TG LVI). By ANOVA, p<0.05 for 1-WT vs WT LVC or TG vs TG LVC; 2-WT vs WT LVI or TG vs TG LVI; 3-WT vs TG; 4-WT LVC vs TG LVC; and 5-WT LVI vs TG LVI. 
Table 1

Echocardiography and Necropsy Results

\begin{tabular}{|c|c|c|c|c|}
\hline & $\begin{array}{c}\text { WT } \\
\text { control } \\
(\mathbf{n}=20)\end{array}$ & $\begin{array}{c}\text { MMP-9 TG } \\
\text { control } \\
(\mathrm{n}=19)\end{array}$ & $\begin{array}{c}\text { WT } \\
5 \text { day MI } \\
(n=16)\end{array}$ & $\begin{array}{c}\text { MMP-9 TG } \\
5 \text { day MI } \\
(n=29)\end{array}$ \\
\hline Body Weight (g) & $27.2 \pm 1.4$ & $28.0 \pm 1.4$ & $23.7 \pm 1.1^{*}$ & $22.6 \pm 0.8^{*}$ \\
\hline Heart Rate (bpm) & $447 \pm 6$ & $455 \pm 8$ & $485 \pm 11$ & $487 \pm 10$ \\
\hline LV Free Wall Thickness (systolic, mm) & $0.96 \pm 0.02$ & $0.97 \pm 0.02$ & $0.62 \pm 0.02 *$ & $0.61 \pm 0.03^{*}$ \\
\hline End Diastolic Volume ( $\mu \mathrm{l})$ & $45 \pm 2$ & $46 \pm 3$ & $83 \pm 4 *$ & $74 \pm 4 *$ \\
\hline End Systolic Volume $(\mu \mathrm{l})$ & $17 \pm 1$ & $18 \pm 1$ & $69 \pm 4^{*}$ & $56 \pm 4^{* \dagger}$ \\
\hline Ejection Fraction (\%) & $61 \pm 2$ & $61 \pm 2$ & $18 \pm 2 *$ & $25 \pm 2 * \dagger$ \\
\hline LV mass (mg) & $81 \pm 3$ & $85 \pm 5$ & $99 \pm 4 *$ & $93 \pm 3$ \\
\hline RV mass (mg) & $19 \pm 1$ & $19 \pm 1$ & $20 \pm 1$ & $18 \pm 1$ \\
\hline Lung wet weight (mg) & $149 \pm 5$ & $126 \pm 4$ & $175 \pm 15$ & $146 \pm 10$ \\
\hline LV mass/ BW ratio (mg/g) & $3.0 \pm 0.1$ & $3.1 \pm 0.1$ & $4.2 \pm 0.1^{*}$ & $4.1 \pm 0.1^{*}$ \\
\hline Infarct Size (\%) & & & $49 \pm 2$ & $49 \pm 2$ \\
\hline
\end{tabular}

Control is day 0 samples. LV- left ventricle; RV- right ventricle;

p $<0.05$ vs control and

$t_{\mathrm{p}<0.05}$ vs WT MI by ANOVA. 